\title{
Los gobernadores civiles en el primer franquismo*
}

\author{
Julio Ponce Alberca
}

Universidad de Sevilla

RESUMEN: Este trabajo tiene por objetivo el estudio de los nombramientos de gobernador civil efectuados entre enero de 1939 y diciembre de 1958. Dicho estudio forma parte de un análisis cuantitativo que muestra la progresiva estabilización del régimen en sus primeros 20 años de vida y sus formas de implantación a escala local. El conjunto de gobernadores civiles constituye un conjunto de personal político significativo del cual se analizan aspectos como la edad, la formación, profesión, trayectoria política anterior y posterior, etc. Igualmente y para cada provincia, se pone de relieve el grado de estabilidad de estos gobernadores medido en función de la duración temporal de sus mandatos. Por último, se hace énfasis en dos aspectos que consideramos relevantes: el primero gira en torno a la variada procedencia y evolución ideológica de aquellos que fueron gobernadores entre 1939 y 1958, aunque todos eran simultáneamente jefes provinciales del Movimiento; el segundo se centra en el comportamiento de los gobernadores con respecto al poder central que les habia delegado la autoridad del mando en una provincia y, también, con respecto a los problemas, necesidades, intereses y, a veces, presiones organizadas de carácter local.

\section{Palabras clave: Franquismo; Estado; Gobiernos Civiles; Política; Administración.}

\section{The Civil Governors in First Francoism}

ABSTRACT: This article is addressed to analyse a relevant group in Francoist State: the civil governors (gobernadores civiles). The period of study (January

* Los resultados que se ofrecen en este trabajo forman parte de las investigaciones llevadas a cabo en el seno del proyecto I+D financiado por el Ministerio de Economía y Competitividad, titulado Poder central y poderes locales en el Sur peninsular durante el primer franquismo, 1939-1958 (HAR 2010-19397). 
1939 and December 1958) covers the first 20 years of dictatorship. This study not only shows the progressive stabilisation of the regime during that period but also how it was established in local frames (provinces). The group analysed represents a significant whole of political personnel and several items have been explored as age, education, profession, previous and subsequent career, etc. The stability of each province has been measured based on the number of governors nominated between 1939 and 1958. This work concludes with some reflections about two important matters: firstly, the ideological provenance and evolution of the governors even though they were provincial chiefs of the Movimiento (the only party also called Falange); and secondly, the performance of governors between the interests of the government that has nominated them and, on the other hand, the problems, needs and pressures came from local spheres.

KeY WORDS: Francoism; State; Civil Governors; Politics; Administration.

\section{INTRODUCCIÓN}

Viene siendo un lugar común la percepción de la historia política de la España contemporánea como una prolongada serie de cambios de régimen. Especialmente, el siglo XX, ofrece una imagen de inestabilidad política determinada por un régimen liberal en descomposición, dos dictaduras, el segundo intento republicano de nuestra historia, una guerra civil y, por fin, una transición democrática que logró consolidarse en medio de no escasas dificultades. Sin embargo, si adoptásemos otro punto de vista, esa visión de continuas alteraciones se matizaría notablemente. Es sabido que las largas tendencias económicas y sociales introducen una corrección sustancial en la pretendida trascendencia de los cambios políticos debido a la persistencia de sus estructuras e inercias. Pero existen otros caminos historiográficos menos recorridos que aportan también sus propios matices. Uno de ellos —en estrecha comunión con la política - es la historia del Estado. El análisis del funcionamiento del Estado, de su estructura, de su legislación y de la aplicación real de la misma, de su composición social y de sus relaciones con el territorio y sus habitantes abre un campo de estudio que consideramos muy fructífero. Es en la estructura concreta del Estado y de su actuación - en un plano distinto al de las formulaciones ideológicas - donde encontramos el origen de buena parte de los problemas del país y de la permanencia de muchos de ellos.

Desde esta óptica, si tomamos la administración local como ángulo de análisis, podemos contemplar un panorama en el que las continuidades superan de largo a las rupturas. Los entes locales - léase ayuntamientos y diputaciones - siempre han estado sujetos a la dependencia y la jerarquía del poder central a través de una figura clave para el control de nuestra organización 
territorial como ha sido el gobernador civil. Es sabido que todos los regímenes han mantenido los gobiernos civiles como máxima autoridad en las provincias, desde mediados del siglo XIX hasta los comienzos de la generalización autonómica. Ni siquiera la Segunda República prescindió de ellos, a excepción de la Cataluña autonómica para la que fue designado un delegado del gobierno. Esos rasgos de dependencia de los entes locales figuraban en las leyes municipal y provincial de 1877 y 1882, en los estatutos municipal y provincial de Calvo Sotelo (1924 y 1925) e, incluso, en la Ley Municipal republicana de 1935. Los gobernadores siempre gozaron, entre sus potestades, de la capacidad de reorganizar las corporaciones locales de acuerdo con el color político gubernamental. Sólo las circunstancias excepcionales de la guerra civil determinaron un relativo cambio de tendencia. En la mayor parte de la zona leal a la República el poder local pasó de hecho a manos de los comités, en detrimento de las autoridades que contemplaron cómo sus potestades se vieron recortadas en términos reales, aunque en las disposiciones oficiales se mantuviera la ficción de una legalidad que había sido desbordada en las primeras semanas de la guerra. Ciertamente, instituciones y normas seguían consagradas en las disposiciones oficiales pero el ejercicio real de la autoridad se vio drásticamente alterado durante los primeros meses de la guerra. No en vano, los gobiernos de Francisco Largo Caballero y, posteriormente, Juan Negrín pusieron gran empeño en restaurar tanto el poder como la autoridad de los gobernadores ante las instituciones locales, esto es: los ayuntamientos y las diputaciones, si bien renombradas entonces bajo la expresión de consejos municipales y consejos provinciales.

Por lo que a este artículo se refiere, cabe señalar que en la zona franquista se produjo un fenómeno sensiblemente inverso. La restauración de las instituciones y del principio de autoridad - alteradas por el propio golpe del $18 \mathrm{de}$ julio - fueron objetivos prioritarios para los sublevados, quienes difundieron un discurso entusiasta de «normalización» de unos servicios públicos que se habían convertido en eficaces y diligentes casi de la noche a la mañana. La divulgación de esa imagen de administración modélica — surgida en pocas semanas- se convirtió en un instrumento más de propaganda contra el enemigo de antes y de después de la guerra. Desde la óptica de la prensa nacional, la República había dañado al Estado politizándolo y corrompiéndolo para hundirlo, después del 18 de julio, en una tempestad revolucionaria protagonizada por los comités donde se disolvieron el orden, la jerarquía institucional y el control del poder por parte del Estado. Se buscaba transmitir e inculcar imágenes de radical contraste entre las dos Españas: en una se estaba construyendo un Nuevo Estado; en la otra, sencillamente, estaba desapareciendo lo que quedaba de autoridad pública en medio de la anarquía. Obviamente, ambas eran exageraciones tan deliberadas como intencionales. Pocos podían negar la evidencia del serio desgaste de las instituciones de la República ante el ímpetu de las 
fuerzas políticas y sindicales, pero el Estado aún mantenía su estructura general, su legalidad y su capacidad de defensa y gestión. Como también era cierto que el Nuevo Estado «nacional», en realidad, no resultaba tan nuevo.

Tras las experiencias de la Junta de Defensa Nacional (julio-octubre 1936) y de la Junta Técnica del Estado (en la que la gobernación fue puesta en manos de un gobernador general a partir de octubre de 1936), el gobierno de enero de 1938 estableció el Ministerio del Interior cuyo titular sería Ramón Serrano Suñer. Entre sus principales objetivos se contaba la configuración de un «nuevo» Estado que, en sus propias palabras, quería aspirar a «... la constitución y proyección de un régimen permanente, de un verdadero régimen de derecho capaz de dar expresión de realidad jurídica ordenada y estable a una verdadera revolución» ${ }^{1}$. Sin embargo, esa «verdadera revolución» no iba a llegar mucho más allá de un retorno a las tradicionales estructuras de organización territorial, tal y como apuntó Pemartín en su disección sobre qué sería «lo nuevo» ${ }^{2}$. Las palabras del ministro Serrano desembocarían en una «realidad jurídica» tan ordenada y estable que la «verdadera revolución se evaporó»; no resultaba extraño pues que el principal colaborador del cuñado de Franco en el ministerio fuera el subsecretario José Lorente Sanz, un prestigioso abogado del Estado, católico y sensiblemente alejado del falangismo doctrinal. A él se debe en gran parte la estructuración de lo que se denominó la «Administración central del Estado».

La instauración del estado franquista terminó por ser una restauración de la organización territorial centralizada conocida en el país desde mediados del siglo XIX. Esto es: ayuntamientos y diputaciones en situación de dependencia jerárquica, mientras los gobernadores civiles se mantuvieron como máxima autoridad de las provincias diseñadas por Javier de Burgos en 1833. Aquella restauración fue escasamente novedosa salvo que se mostró aún más jerárquica y centralizadora al reforzar la figura del Gobernador Civil. Siendo esto así, se comprende que un estudio pormenorizado de los gobiernos civiles sea capaz de ofrecernos una imagen más detallada de la instalación del primer franquismo a escala local ${ }^{3}$.

1 SERRANO SUÑER, 1947: 67. También SERRANO SUÑER, 1978: 181.

2 PEMARTÍN, 1940.

3 Sobre los gobiernos civiles y los gobernadores tenemos una bibliografía cada vez más abundante, si bien aún es mucho el camino que queda por recorrer. Como simple selección caben ser citados: CAJAL VALERO, 1999. CALVO VICENTE, 1993, vol. I: 19-28. CLARA, $\mathrm{n}^{\circ} 18$ (2002): 451-468. CLARA, $\mathrm{n}^{\circ} 20$ (2004): 143-166. CLARA, $\mathrm{n}^{\circ} 23$ (2007): 573-596. DÓRIGA TOVAR, no 156 (nov/dic 1967): pp. 145-167. GARCÍA MAÑÁ, 1986. GONZÁLEZ MADRID, 2005. MARÍN I CORBERA, nº 29 (Enero/Junio 2013): 269-299. MERCADAL BAGUR, 1998. MIRAMBELL I BELLOC, 1992. MORENO SÁEZ, n 2 (2000): 71130. NAVAJAS ZUBELDIA y RIVERO NOVAL, $\mathrm{n}^{\circ} 128$ (1995): 215-228. NICOLÁS MARÍN, 1993: 135-150. ORTIZ HERAS, 1995, vol. I: 181-188. PÉREZ DE LA CANAL, 1964. 


\section{PeRFILES DE LOS GOBERNADORES CIVILES (1939-1958)}

Resulta obligado un somero análisis cuantitativo de los gobernadores civiles durante el primer franquismo antes de abordar los problemas locales de consolidación del nuevo régimen. El conjunto que aquí analizamos es el integrado por todos los gobernadores en activo entre el $1^{\circ}$ de enero de 1939 y el 31 de diciembre de 1958. La justificación de estas fechas descansa en dos hitos: el comienzo del último año de la guerra y el final de 1958, año de la aparición del decreto de gobernadores (10 de octubre). En consecuencia, el período que se viene conociendo como «primer franquismo» se amplía aquí, a efectos de nuestro análisis, hasta la aparición del mencionado decreto que reforzó el papel de los gobernadores como impulsores del desarrollo socioeconómico de las provincias.

Según los datos recopilados, sabemos que se produjeron 315 designaciones de gobernadores entre 1939 y 1958. Naturalmente, este número de designaciones coincide con el número de registros de nuestra base de datos, pero no debemos confundir esa cifra con el número real de gobernadores puesto que buen número de ellos repitieron cargo en otras provincias. Es decir, un mismo gobernador pudo recibir cuatro nombramientos en el período analizado $\mathrm{y}$, por consiguiente, aparece en la base de datos en cuatro registros. De hecho, según nuestros cálculos, fueron 216 las personas que ejercieron el cargo de gobernador entre 1939 y 1958. Toda la base de datos ha sido construida preferentemente a partir de los nombramientos oficiales en el Boletín Oficial del Estado ${ }^{4}$.

A estos 216 gobernadores podríamos sumar algunos que ya venían desempeñando el cargo a fecha $1^{\circ}$ de enero de 1939 , con lo cual obtendríamos una cifra mayor. Por claridad y coherencia del grupo analizado, hemos preferido limitar el estudio de los designados a partir del $1^{\circ}$ de enero de 1939 . No obs-

PONCE ALBERCA, 2008. PONCE ALBERCA, 2009: 99-122. PONCE ALBERCA, 2012: 96-109. RICHARD, tomo VIII (1972): 441-474. RISQUES, 1995. RISQUES, 2012; SANZ ALBEROLA, 1999. SERRALLONGA I URQUIDI, $\mathrm{n}^{\circ} 7$ (2007). TÉBAR HURTADO, 2011. VEGA SOMBRÍA, 2005. VV.AA., 1997. Sobre el franquismo a escala local, entre otros, ver los trabajos de: NICOLÁS MARÍN, no 33 (1999): 65-86. SÁNCHEZ BRUN, 2002. GARCÍA RAMOS, 2003. CERÓN TORREBLANCA, 2007. COBO ROMERO y ORTEGA LÓPEZ, 2005. RODRÍGUEZ GONZÁLEZ, 2003.

4 En esta cifra se recogen también los nombramientos oficiales de gobernadores "fugaces". Un ejemplo es el de Manuel Mora Figueroa que fue oficialmente gobernador de Madrid entre mayo y julio de 1941, pero que apenas tomó posesión efectiva del cargo al marchar a la División Azul. Otro ejemplo fue la designación oficial del historiador Melchor Fernández Almagro como gobernador de Baleares en abril de 1940 quien no tomó posesión produciéndose su cese tan solo unos días más tarde. Es posible que la cifra de 315 designaciones pueda variar levemente con la inclusión de algún nombramiento que pudiera haberse pasado por alto, pero es improbable que varíe el número de gobernadores (216) y apenas afectará a las tendencias generales que se ofrecen en este trabajo. 
tante, es preciso advertir que hubo gobernadores nombrados antes de $1939 \mathrm{y}$ que permanecieron en el cargo hasta bien entrado el período analizado: es el caso de Jesús Cagigal Gutiérrez, gobernador civil de Logroño desde agosto de 1938 hasta noviembre de 1944. Es resumen: este análisis se realizará sobre las 315 designaciones mencionadas o, en otras palabras, los 216 gobernadores nombrados entre 1939 y 1958.

Una primera característica a destacar es la frecuencia anual con la que se produjeron esos 315 nombramientos entre 1939 y 1958 . No todos los años registraron un número similar de nombramientos. En efecto, más de un $50 \%$ de todos ellos tuvo lugar en los primeros seis años de régimen, tal y como se observa en la siguiente tabla:

TABLA 1. Número de nombramientos de gobernadores por año (1939-1958)

AÑo \begin{tabular}{|l|l|l|l|l|l|l|l|l|l|l|l|l|l|l|l|l|l|l|l|}
\hline $\mathbf{3 9}$ & $\mathbf{4 0}$ & $\mathbf{4 1}$ & $\mathbf{4 2}$ & $\mathbf{4 3}$ & $\mathbf{4 4}$ & $\mathbf{4 5}$ & $\mathbf{4 6}$ & $\mathbf{4 7}$ & $\mathbf{4 8}$ & $\mathbf{4 9}$ & $\mathbf{5 0}$ & $\mathbf{5 1}$ & $\mathbf{5 2}$ & $\mathbf{5 3}$ & $\mathbf{5 4}$ & $\mathbf{5 5}$ & $\mathbf{5 6}$ & $\mathbf{5 7}$ & $\mathbf{5 8}$ \\
\hline 49 & 28 & 29 & 18 & 22 & 17 & 15 & 14 & 8 & 5 & 10 & 9 & 17 & 6 & 8 & 12 & 1 & 25 & 12 & 10 \\
\hline
\end{tabular}

Fuente: Nombramientos en BOE. Elaboración propia.

En lo esencial, las cifras anteriores coinciden con los datos publicados hace años por Carles Viver que recogió el número de ceses por año ${ }^{5}$. La frecuencia irregular de nombramientos nos da una idea del grado de inestabilidad registrada durante los primeros años de dictadura en lo que a rotación de personas en cargos públicos se refiere. El primer lustro de franquismo registró numerosos nombramientos a nivel de direcciones generales o subsecretarías $y$, en la escala provincial, podemos rastrear la misma tendencia en los máximos representantes del gobierno. Esa alta frecuencia de nombramientos fue un eco de las luchas políticas que se desarrollaron en el interior de un régimen en proceso de definición. A ello hemos de añadir que ni el gobierno siempre acertó en la elección de gobernadores idóneos y sintonizados con el poder central, ni éstos siempre tuvieron éxito en su gestión ante las fuerzas locales. Esas fueron las causas de buena parte de los ceses. Pero hay que advertir que no todos los ceses significaban el fin de una carrera política; es decir, con frecuencia los gobernadores rotaban de una provincia a otra con lo que, si bien puede hablarse de inestabilidad en el cargo, el grado de «renovación»

5 Allí se ofrecen los siguientes de ceses por año: 1939 (33), 1940 (27), 1941 (29), 1942 (18), 1943 (22), 1944 (17), 1945 (15). El único año que ofrece una discrepancia notable es el año 1939 y ello se explica en gran medida porque el $1^{\circ}$ de abril de aquel año se nombraron gobernadores para las últimas provincias conquistadas por los nacionales, no llegándose a publicar ni siquiera los ceses de los gobernadores republicanos. Vid.: VIVER PI-SUNYER, 1978: 215, cuadro 2. 
real del personal político que desempeñó gobiernos civiles fue más reducido. Si tomamos los 49 nombramientos que se realizaron en 1939, observamos que 11 de ellos recayeron en gobernadores que volverían a serlo con posterioridad en tres o más ocasiones.

$\mathrm{Al}$ analizar con detalle los 315 nombramientos efectuados, podemos extraer el número real de gobernadores que se encuentran dentro de esa cifra, una vez depurados los nombrados varias veces para diversos gobiernos civiles. El siguiente cuadro expresa el grado de repetición de esos mandatos.

TABLA 2. Número de nombramientos y de gobernadores clasificado por frecuencia de mandatos (1939-1958)

\begin{tabular}{|l|c|c|c|r|}
\cline { 2 - 5 } \multicolumn{1}{c|}{} & NOMBRAMIENTOS & $\%$ & GOBERNADORES & $\%$ \\
\hline 1 mandato & 113 & 35,87 & 113 & 52,31 \\
\hline 2 mandatos & 113 & 35,87 & 65 & 30,09 \\
\hline 3 mandatos & 58 & 18,41 & 28 & 12,96 \\
\hline 4 mandatos & 20 & 6,35 & 7 & 3,24 \\
\hline 5 mandatos & 11 & 3,49 & 3 & 1,39 \\
\hline TOTAL REGISTROS & 315 & 99,99 & 216 & 99,99 \\
\hline
\end{tabular}

Fuente: Nombramiento en BOE. Elaboración propia.

Como puede observarse, los 315 nombramientos recayeron en realidad sobre 216 personas. De entre ellas, 113 sólo fueron gobernadores en una sola ocasión, lo que representa un porcentaje del 52,31\% sobre el total de 216 gobernadores. Con dos mandatos aparecen 65 gobernadores, aunque hay que matizar que una minoría de ellos prolongó uno de los dos fuera de dicho período, habitualmente con posterioridad. El número de personas que fueron en tres ocasiones gobernadores se reduce a 28 , teniendo al menos 13 de ellas todos sus mandatos como gobernadores dentro el período analizado, mientras el resto disfrutaron de alguno o algunos de sus mandatos fuera de ese tramo cronológico. Sólo siete gobernadores lo fueron en cuatro mandatos (cuatro siempre dentro del período y tres con algún mandato anterior o posterior). Y, por último, sólo 3 gobernadores repitieron cargo en cinco ocasiones. Como podía esperarse, ninguno de éstos últimos desempeñaron la totalidad de sus cinco mandatos entre 1939 y 1958: uno de ello ya lo era durante la guerra y dos de ellos lo serían durante los años sesenta.

Si fijamos nuestra atención en los nombramientos y aparte de los gobernadores que lo serían una sola vez, comprobamos que la mayor parte de los designados tuvieron entre dos y tres mandatos. Y es que, con el transcurso del tiempo, la experiencia previa y la adecuación de la persona al cargo se irían 
convirtiendo en uno de los criterios del gobierno para realizar los nombramientos. La inestabilidad inicial del régimen vuelve a confirmarse si analizamos los 113 gobernadores que lo fueron una sola vez. Un $71 \%$ de ellos ocuparon el cargo antes de diciembre de 1945; sin embargo, solo 33 de esos gobernadores de un solo mandato fue nombrado entre 1946 y 1958. La inestabilidad de gobernadores en los primeros años, aunque incuestionable, debe ser matizada por el traslado de algunos de ellos a puestos de mayor responsabilidad. Eso le ocurrió a Luis Alarcón de la Lastra (gobernador de Madrid entre abril y agosto de 1939) que pasó a ser ministro de Industria. En otras palabras: en la medida en que se consolidó el régimen se fue conformando un conjunto relativamente estable de gobernadores que eran trasladados de una provincia a otra. Obviamente, ello no excluyó la incorporación de nuevos gobernadores.

TABLA 3. Número de nombramientos anuales y meses de permanencia media de los designados cada año (1939-1958)

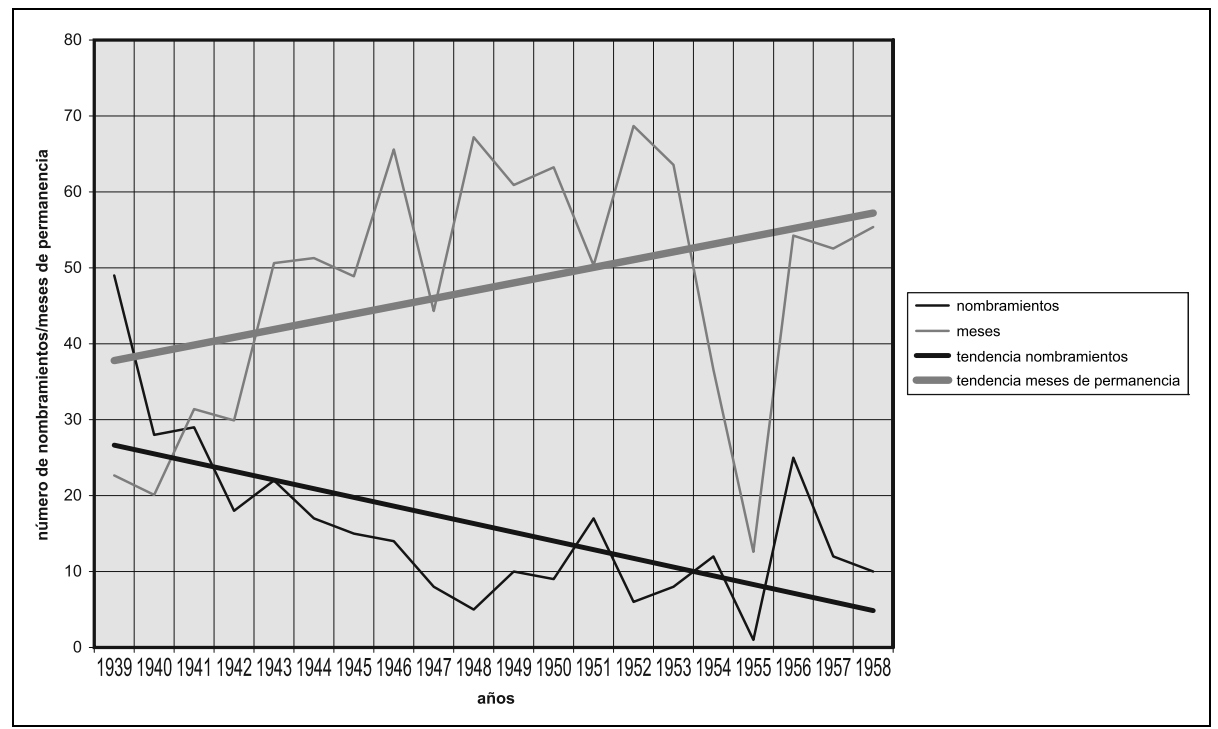

Fuente: Nombramientos en BOE. Elaboración propia.

Otro dato también resulta elocuente y viene a confirmar el panorama descrito: la permanencia media de los gobernadores en su destino fue creciendo conforme pasaban los años. Los gobernadores nombrados en 1939 duraron una media de 1,89 años, mientras que la duración en el cargo de los designados en 1943 aumentó hasta 4,22 años y, para los de 1953, dicha media rondaba ya los 5,30 años. Posteriormente hubo años en los que la media se redujo 
levemente debiendo descontar el singular año de 1955 porque sólo se produjo un nombramiento y es poco representativo. La tendencia creciente de la estabilidad (medida en meses de permanencia de los nombrados cada año) y la tendencia descendente del número de los designados cada año se manifiestan claramente en la tabla 3.

La duración de los gobernadores en el conjunto del primer franquismo se situó en torno a los tres años y medio entre 1939 y 1958, un promedio muy superior a la fugacidad de los gobernadores en períodos anteriores como la Restauración o la República, en los que el juego de partidos y la inestabilidad política se reflejaban en la velocidad de los reemplazos en este tipo de cargos de confianza gubernamental. Ahora bien, las tendencias apuntadas sobre aquellos gobernadores tiene otra lectura: la geográfica. ¿Qué provincias se destacaron en la clasificación de gobiernos civiles inestables? O por el contrario: ¿en qué lugares la permanencia media de los gobernadores fue más elevada?

El siguiente mapa nos ofrece una imagen que contribuye a despejar estos interrogantes. Y, como puede comprobarse, del comportamiento provincial en términos de estabilidad/inestabilidad no parecen inferirse pautas regionales claras.

MAPA 1. Número de gobernadores nombrados en cada provincia (1939-1958)

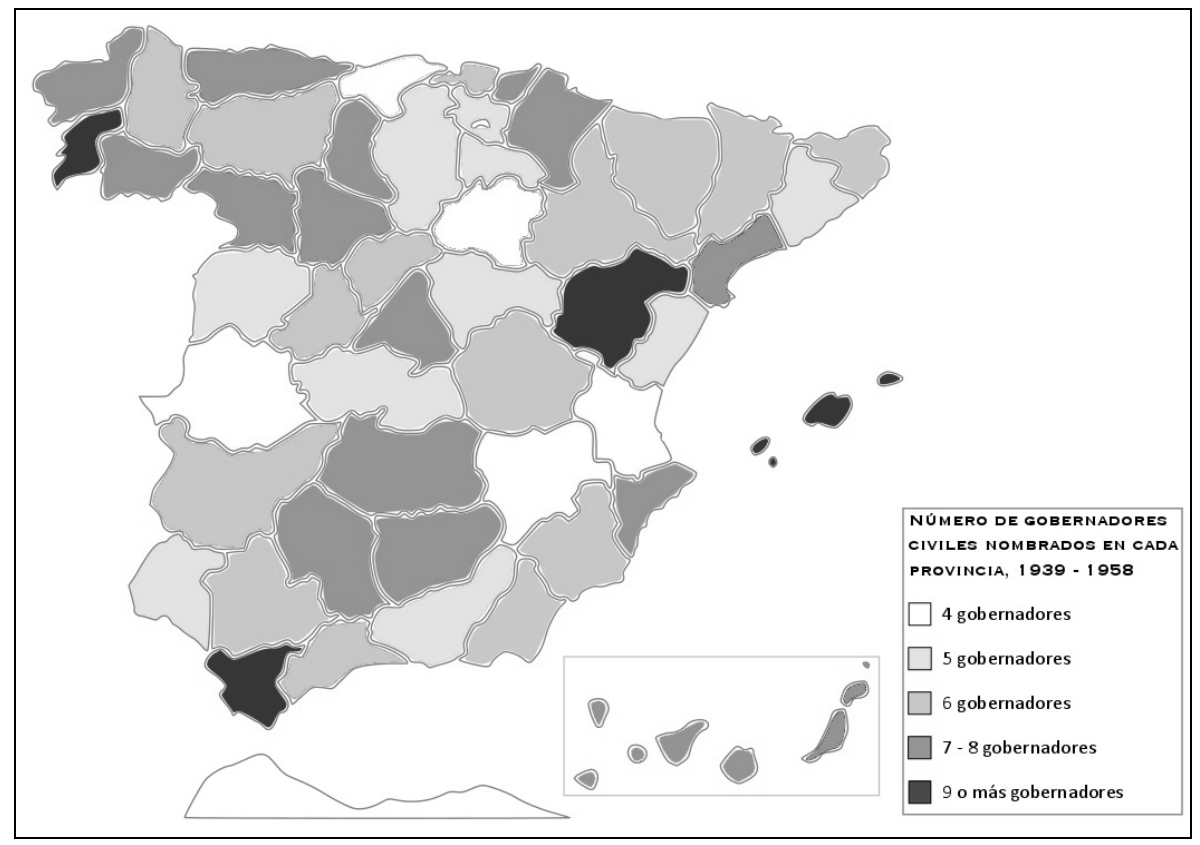

Fuente: Nombramientos en BOE. Elaboración propia. 
De las 50 provincias, cuatro se mostraron especialmente inestables: Cádiz, Baleares, Teruel y Pontevedra). La tónica general fue contar entre seis y ocho gobernadores a lo largo de estos 20 años, lo que concuerda con la media de algo más de tres años de permanencia. El $60 \%$ de las provincias se encontraba en esa situación. Diez provincias fueron medianamente estables (con cinco gobernadores destinados), muy heterogéneas entre sí: Barcelona, Huelva, Granada, Salamanca o Burgos. Y, por último, cabe destacar que Albacete, Cáceres, Santander, Soria y Valencia se mostraron como las provincias en las que los gobernadores disfrutaron de mayores mandatos. Con toda probabilidad, buena parte de la explicación de estas variedades provinciales haya que buscarla en la política local, sus condicionantes e intereses, sus relaciones con los representantes del Estado central y la habilidad de gobernadores y autoridades locales para establecer unos equilibrios perdurables. Es evidente que estas explicaciones habrán de ser verificadas caso por caso, pero no es arriesgado afirmar que las complejas relaciones entre los gobernadores y la política provincial debieron ser determinantes. Unas relaciones no exentas de conflictos y tensiones pese a la organización jerárquica del régimen franquista.

Otra variable de interés es la edad de los designados. Actualmente, conocemos el año de nacimiento de 138 de los 216 gobernadores lo que representa una muestra razonablemente significativa. El año promedio de nacimiento gira en torno a 1906 y alrededor de un 70\% nacieron entre 1900 y 1919. La mayor parte, pues, pertenecía a lo que Gil Pecharromán ha denominado la primera generación del Movimiento, aunque ya se advierte en los años cincuenta el afloramiento de hombres pertenecientes a la segunda generación - los nacidos en los años veinte- a los que se les conoció como generación del silencio $^{6}$. En términos de edad, apenas se detectan ligeras diferencias entre los gobernadores en función de las veces que repitieron cargo. Aquellos que ostentaron un solo mandato nacieron en torno a 1904 de media, mientras que los que tuvieron cuatro o más mandatos —una minoría inferior al 5\% - registran apenas un año más como promedio. Sin embargo, los que fueron gobernadores entre dos y tres veces (en torno a un $42 \%$ del total de gobernadores del período) nacieron en torno a 1908, lo que parece apuntar a una cierta correlación inversa entre la edad y la posibilidad de repetición en el cargo. En términos generales, podemos afirmar que pertenecieron a una generación que vivió la expansión material de la dictadura primorriverista y su juventud estuvo marcada por la Segunda República y la guerra civil. La mayor parte de ellos estaban adscritos al espectro de las derechas antirrepublicanas y muchos se destacaron por su participación en la guerra al lado de los sublevados. Con todo, es preciso advertir — en virtud de los datos biográficos hasta ahora dis-

\footnotetext{
6 GIL PECHARROMÁN, 2013: 37.
} 
ponibles - que no parece que más de un tercio fueran excombatientes. No obstante, también resulta obligado señalar que aunque no parece que el haber participado en la contienda fuera un criterio exclusivo para su selección, sí se detecta un incremento en el porcentaje relativo de excombatientes en aquellos grupos de gobernadores con dos, tres y cuatro mandatos. Haber prestado su contribución activa a la victoria no dejaría de ser un elemento de cierta importancia a la hora de repetir la designación para cargos de confianza o, en su caso, para ser promocionado a responsabilidades superiores a la de gobernador de una provincia.

Con respecto al nivel de estudios y la profesión desempeñada, es de destacar que un porcentaje extraordinariamente elevado tenían estudios universitarios o equiparables (academias militares), según los datos disponibles ${ }^{7}$. De los 216 gobernadores conocemos los estudios y la profesión de un $88 \%$, con lo cual la muestra es sobradamente representativa. Hablamos de estudios y profesión porque solían estar estrechamente relacionados, incluso antes de convertirse en gobernadores. Y pueden distinguirse cinco grandes grupos: los profesionales del derecho (un 42\%), los militares (un 36\%), los médicos (alrededor de un 5\%), los ingenieros (otros 5\%) y un último conjunto conformado por otros profesionales (11\%), entre los que se contaban dos arquitectos, dos doctores en Ciencias Químicas, un doctor en Filosofía, dos profesores, un inspector de Enseñanza Media, varios periodistas, etc. Es decir, los profesionales del derecho y, en segundo lugar, los militares fueron - con diferencialos sectores de extracción de gobernadores civiles.

Entre los profesionales del derecho abundaban funcionarios como abogados del estado, notarios, fiscales, magistrados, registradores de la propiedad, catedráticos, etc. Los militares estaban representados por oficiales con grado de comandante o superior, pertenecientes a Infantería, Caballería, Ingenieros y un número sensible de jurídicos militares, lo que acentuaba la presencia de gobernadores con formación jurídica. Un ejemplo de mezcla entre ambos grupos fue Francisco Sáenz de Tejada y Olózaga, barón de Benasque, gobernador en cinco ocasiones entre 1937 y 1952 que fue excombatiente, oficial de complemento y magistrado del Tribunal Supremo. Ante esa notoria frecuencia de universitarios de formación jurídica, parece percibirse una tendencia hacia la búsqueda de cierta habilitación profesional para servir al régimen en el cargo de Gobernador Civil. La dictadura buscaba burócratas fieles al sistema para ser los encargados de gobernar las provincias y, en gran medida, su

7 La formación universitaria alcanzaba, como mínimo, al 95\% de las personas que fueron nombradas gobernadores en los años estudiados. Hubo excepciones, como el banderillero Joaquín Miranda González (gobernador de Huelva entre 1938 y 1943) o, probablemente, el industrial Luis Julve Ceperuelo, que fue gobernador en cuatro ocasiones entre 1942 y 1958 (Huesca, Cáceres, Castellón y Málaga). 
función se encontraba estrechamente vinculada a la gestión administrativa, dentro de un marco político sensiblemente restringido a la pertenencia oficial al partido único. Ciertamente, como apuntó en su día Ortiz Heras, los gobiernos civiles fueron los pilares más importantes del régimen en las provincias ${ }^{8}$. Pero no resulta tan nítida la imagen del gobernador como un exponente diáfano de liderazgo y, al respecto, es importante no sobreestimar el concepto de liderazgo en el marco del ejercicio de una autoridad delegada cuyo poder, al fin y al cabo, procedía de las atribuciones conferidas por el gobierno. En otras palabras: el gobernador aparecía ante su provincia investido de una enorme autoridad, pero no dejaba de ser un enviado al que se debía admitir y obedecer. Podía ocurrir - y, de hecho, ocurrió en algunas ocasiones - que el gobernador no terminase de encajar en la provincia de destino u originase más problemas que soluciones, ante lo cual el Ministerio de la Gobernación procedía casi siempre a su reemplazo. La alta frecuencia de relevos de gobernadores en algunas provincias es una buena muestra de ello.

La presencia de burócratas entre los gobernadores no era excepcional como tampoco lo era en el conjunto del personal político del régimen. Disponemos de algunos datos al respecto gracias a una serie de trabajos elaborados a partir de los años setenta y ochenta desde la óptica del derecho o la ciencia política ${ }^{9}$. Los resultados de estas investigaciones constataron la presencia de una élite burocrática española dominante en el estado franquista, precisando Julián Álvarez que la emergencia de dicha élite se favoreció dentro de un panorama marcado por la ausencia de partidos políticos y la falta de hegemonía de la sociedad civil. Con independencia de los motivos, lo cierto es que el estado franquista pasó a estar en manos de una élite burocrática y funcionarial, probablemente en un mayor grado que durante la República o la anterior dictadura de Primo de Rivera. Dicho grupo funcionarial dirigente estaba integrado por una constelación de cuerpos especiales, con fórmulas de acceso diversas y una tendencia a la promoción por estricta antigüedad que reforzaba la cohesión y el espíritu corporativo. Entre ellos se contaban, por ejemplo, catedráticos de universidad, abogados del estado y letrados del Consejo de Estado $^{10}$. Una simple cuantificación general de esa presencia de burócratas en el aparato estatal resulta elocuente: para 1965 había un 90\% de altos funcionarios en puestos políticos ejecutivos. Ciertamente, esa cifra descendería hacia finales del régimen (para 1971 se contabilizaba un porcentaje de un $70 \%$ ) y caería aún más posteriormente cuando los puestos de libre designación -

8 ORTIZ HERAS, 1995: 181.

9 Sobre la burocracia: ÁlVAREZ ÁlVAREZ, 1984. BAENA DEL ALCÁZAR, 1999. BAÑÓN MARTÍNEZ, 1978. BELTRÁN VILLALBA, 1977. NIETO GARCÍA, 1974. PERNAUTE, 1978.

10 ÁLVAREZ ÁLVAREZ, 1984: 113-114 y 117. 
extraídos en parte de altos funcionarios - interpondrían un área de confianza entre los responsables políticos y la estructura administrativa ${ }^{11}$. Por su parte, Miguel Beltrán señala que, para 1971, procedían de la élite burocrática un $62 \%$ de los ministros, un 53\% de los subsecretarios, un $79 \%$ de los directores generales y secretarios generales técnicos, aunque sólo un $24 \%$ de los gobernadores civiles ${ }^{12}$. El relativamente reducido número de altos funcionarios entre los gobernadores del tardofranquismo parece desvelar una evolución del perfil socio profesional de los gobernadores civiles si los comparamos con los de las primeras décadas de la dictadura. No obstante, merece subrayarse la lógica mayor presencia de la élite burocrática conforme ascendemos en la escala de cargos políticos. De hecho, un ascenso anhelado para todo gobernador válido y cualificado era convertirse en secretario general técnico o director general.

Quizás entendamos mejor esa presencia relativamente limitada de altos funcionarios entre los gobernadores civiles si formulamos algunas observaciones a las mencionadas obras sobre la élite burocrática. Así y pese a la validez de estos estudios, todos ellos se refieren a la élite burocrática entendida ésta como los altos funcionarios civiles de la Administración central. Es decir, dejan fuera ciertos grupos burocráticos que también desempeñaron un papel importante durante el franquismo como, por ejemplo, los militares o los empleados del Movimiento. Afortunadamente disponemos de algunos trabajos recientes que corrigen esta distorsión, destacándose el de Francisco Bernal García sobre el sindicalismo vertical, auténtica plataforma de personal político que disponía de cuerpos técnicos sindicales cuyos miembros podían conseguir una promoción hacia otros puestos de la Organización Sindical Española (OSE), hacia el partido o hacia el Estado ${ }^{13}$. De hecho, no pocos gobernadores civiles procedían de cargos previos ejercidos en el seno del sindicalismo vertical o en las múltiples estructuras del partido (delegados nacionales de Sindicatos o Provincias, delegados provinciales, etcétera).

Tras el marco expuesto resulta pertinente esbozar algunos apuntes sobre los cargos anteriores y posteriores desempeñados por quienes fueron o serían designados gobernadores civiles, toda vez que en muchos casos se verifica que estos cargos eran un peldaño más dentro de una carrera política de prolongación variable. Hemos de advertir que trabajamos con muestras por cuanto conocemos la trayectoria pública anterior de un 58\% de los 216 gobernadores y la posterior en un $49 \%$ de los casos. En consecuencia y aunque son representativas las muestras, lo que vamos a ofrecer son unas tendencias generales que entendemos serán verificadas o matizadas en la medida en que

11 BELTRÁN VILLALBA, 1977: 51-52.

12 Ibid.: 55-56.

13 BERNAL GARCÍA: 2010. 
dispongamos de más datos y más detallados. La primera conclusión que se alcanza en función de los datos disponibles es que la experiencia previa en cargos públicos de los gobernadores crece conforme pasan los años, algo lógico si tenemos en cuenta que los designados en 1939 para dirigir un Gobierno Civil apenas habían ocupado cargos con anterioridad. Esa inexperiencia contribuyó al fracaso de muchos de aquellos que ostentaron un solo mandato en los años cuarenta. Si observamos los gobernadores que ejercieron como tales entre 1939 y 1943 comprobamos su heterogénea experiencia previa. Algunos habían sido gobernadores durante la dictadura primorriverista (los casos de Antonio Almagro Méndez en Burgos o Wenceslao González Oliveros en Barcelona). Otros fueron concejales o alcaldes también durante los años veinte (Daniel Arriaza Goñi, Francisco Pérez Cordero, Antonio Iturmendi Bañales, Antonio Parellada, Antonio Gallego Burín, José Garrán Moso o Manuel García del Olmo). En menor medida, detectamos algunos diputados derechistas durante la Segunda República (los casos de Juan Antonio Cremades Arroyo o Juan Granell Pascual). Pero, en su inmensa mayoría, los primeros gobernadores del franquismo no habían tenido experiencia en cargos políticos antes de 1936 (recordemos que la mayor parte de ellos nació entre 1900 y 1919). Tan solo puede señalarse una cierta experiencia adquirida al calor de la guerra en el ejército y, sobre todo, en FET-JONS: Julio Muñoz de Aguilar (miembro de la Junta Política), Mateo Torres Bestard (delegado nacional de Juventudes en 1937), Florencio Acevedo (jefe provincial de Teruel), José Antonio Elola-Olaso (delegado nacional del Frente de Juventudes), Rogelio Vignote (fundador del partido en Córdoba) o Ramón Ferreiro (organizador del partido en Jaén).

Estas características persisten entre los gobernadores hasta 1945, si bien con dos matices. El primero es que crece la presencia de gobernadores que habían tenido experiencias políticas previas en el partido: José Manuel Pardo de Santayana (consejero nacional del Sindicato Español Universitario, SEU), Genaro Riestra Díaz (delegado del Servicio Exterior), Ramón Laporta Girón (inspector general del Movimiento), Heliodoro Fernández Canepa (delegado nacional del SEU), José María Fontana Tarrats (jefe nacional del Sindicato Textil) o Diego Salas Pombo (secretario nacional del SEU). El segundo matiz es que comienzan a aparecer gobernadores que habían sido alcaldes y concejales en los primeros años del régimen: José del Valle Vázquez (alcalde de Santiago de Compostela y gestor provincial) o José Macián Pérez (alcalde de Tarragona).

A partir de 1946 y hasta el final del período aquí analizado (1958), se consolidan progresivamente los dos grandes grupos de extracción de gobernadores: el partido y la política local. Procedentes de cargos en FET-JONS fueron, por ejemplo: Juan Murillo de Valdivia (delegado provincial de Mutualidades Laborales en 1953 que sería posteriormente tres veces gobernador hasta 1970), Eladio Perlado Cadavieco (vicesecretario general de Obras Sindicales 
e inspector nacional de Sindicatos, un funcionario de la OSE que sería luego también tres veces gobernador hasta 1969) o Antonio Soler Bans (delegado provincial de Sindicatos en Albacete y Segovia, entre otros cargos, que sería gobernador desde 1957 hasta 1968 en Cádiz, Murcia y Granada consecutivamente). De la responsabilidad en instituciones locales procedieron gobernadores como David Herrero Lozano (presidente de la Diputación de Segovia), Manuel Urbina Carrera (alcalde de Torrelavega), Luis Julve (presidente de la Diputación de Teruel), José García Hernández (presidente de la Diputación de Guadalajara), Gabriel Juliá Andreu (vicepresidente de la Diputación de Barcelona), José María Pagés Costart (presidente de la Diputación de Lérida), Alfonso Cruz Conde (alcalde de Córdoba), Evaristo Martín Freire (presidente de la Diputación de Ciudad Real), Miguel Moscardó (concejal en el Ayuntamiento de Madrid), José Ramón Herrero Fontana, (concejal en Logroño), etcétera.

Con respecto a la trayectoria posterior seguida por los ex gobernadores, siempre según la información recopilada a la fecha, podemos afirmar que la mayor parte de los gobernadores prosiguieron una carrera política, si bien de calidad e importancia variables. Obviamente, hubo una minoría que no permaneció en la vida política volviendo a su puesto de trabajo oficial o a la actividad privada (por ejemplo José Clavero que se reiró a Cazalla de la Sierra como notario en 1947). Pero según la muestra analizada, puede sugerirse con fundamento que fueron tres los destinos principales con posterioridad al hecho de ser gobernador. Y subrayamos después de ser gobernador porque una de las formas de continuación de la carrera política de un gobernador civil consistía precisamente en ser destinado a otra provincia.

El primer tipo de destino - por cierto, minoritario - era el constituido por aquellos ex gobernadores que dejaron de serlo para ocupar puestos de confianza en la política local como alcaldes o presidentes de Diputación de designación gubernativa. Otro grupo retornaba a cargos de importancia en el partido como delegados nacionales, aunque esa vuelta al partido solía ser un paso transitorio para alcanzar altos cargos en el Estado, habitualmente director general. Un ejemplo fue Alberto Martín Gamero, gobernador entre 1944 y 1956, que fue nombrado delegado nacional de Información e Investigación (1956-57) para, posteriormente, convertirse en secretario técnico del Ministerio de Vivienda, inspector y, luego, director general del mismo departamento, director general de la Oficina de Información Diplomática, cónsul general de España en Nueva York y embajador en Suiza.

El tercer y principal destino de los ex gobernadores era su promoción directa hacia cargos en el Estado. Algunos de esos cargos venían determinados por el partido (Comisario Nacional del Paro, Consejero del Instituto Nacional de Previsión) y otros estaban esencialmente adscritos al Estado como director general, subsecretario e, incluso, ministro. Es bien conocido el caso de Carlos Arias Navarro que fue tres veces gobernador entre 1944 y 1957 en León, Te- 
nerife y Navarra. Siendo además fiscal y notario, se convirtió en director general de Seguridad en 1957, alcalde de Madrid en 1965 y, años más tarde, en ministro de la Gobernación (1973) y presidente del Gobierno (1974-1976).

Para concluir este apartado de perfiles de gobernadores, es preciso señalar que al menos un 43\% de los que ejercieron ese cargo entre 1939 y 1958 fueron en algún momento de su carrera consejeros nacionales del Movimiento y no menos de un 56\% fueron procuradores en Cortes ${ }^{14}$. Dados esos significativos porcentajes (que es muy probable que sean aún mayores en la medida en que avance la investigación) podría resultar interesante estudiar con mayor detalle el papel desempeñado por estos hombres tanto como procuradores como, sobre todo, como consejeros electos por una provincia determinada (que solía ser la de origen, no la de alguno de sus destinos como gobernador). Hasta aquí algunos de los rasgos más relevantes de aquellos gobernadores del primer franquismo que, mayoritariamente, eran oriundos de Andalucía, Castilla La Vieja y Madrid, seguidos de Aragón, Santander y Galicia. Todos esos territorios agrupaban al menos un $60 \%$ de los gobernadores según la muestra obtenida de nuestra base de datos. Ahora bien: ¿cómo actuaron al frente de sus provincias?

\section{LA DIFÍCIL CONSTRUCCIÓN DEL «NUEVO ESTADO»: DE LOS CONFLICTOS A LA NORMALIZACIÓN}

No hemos analizado en el epígrafe anterior la filiación política de los gobernadores. Y no lo hemos hecho deliberadamente puesto que el asunto de la relación entre el partido único y el Estado es complejo hasta tal punto que ha dificultado tanto la comprensión del papel real desempeñado por FET-JONS como la naturaleza de la dictadura franquista (régimen totalitario, autoritario, fascistizado, etc) $)^{15}$. Por añadidura, la controversia pública ha interferido el análisis histórico hasta el punto que algunos han considerado imprescindible utilizar calificativos sobre el régimen en función de escalas de condena o exculpación. Resulta conveniente recordar que no fue menos brutal el establecimiento de aquella dictadura por presentar caracteres de sistema autoritario, como tampoco resultó más represiva por las tentaciones totalitarias de sus primeros años.

14 Entre los estudios sobre los procuradores en Cortes - además de la ya citada obra de Rafael Bañón- merecen señalarse: MAESTRE ROSA, 1977. DÁVILA Y FERNÁNDEZ DE CELIS, 1971. DIAZ NOSTY, 1972. GARRORENA MORALES, 1977. SERRATS URQUIZA, 1974. Aunque fuera del período del primer franquismo, también resulta de interés: AGUILAR, 1976.

15 Una breve pero interesante reflexión en BALFOUR, 2008; 39-43. 
Lejos de controversias ideológicas y dentro de los debates historiográficos sobre la caracterización de la dictadura franquista, consideramos útiles las contribuciones que puede proporcionarnos el estudio de la implantación del régimen a escala local. Así, desde la perspectiva de la máxima autoridad en las provincias, creemos que pueden extraerse algunas conclusiones que pueden enriquecer las respuestas a los siguientes interrogantes: ¿a qué modelo respondió la dictadura de Franco en 1939 y 1958? ¿Realmente la intensa presencia del partido único significó el establecimiento de un régimen fascista o de corte totalitario? ¿Nos muestran las provincias durante los cuatro primeros lustros de existencia de la dictadura la imagen de un proceso de consolidación de un régimen fascista?

Para intentar esclarecer estos interrogantes $-\mathrm{y}$ con las limitaciones de extensión propias de un artículo como este- queremos plantear dos consideraciones generales sobre el primer franquismo y su consolidación desde la óptica de los gobiernos civiles. La primera gira en torno a la variada procedencia y evolución ideológica de aquellos que fueron gobernadores entre 1939 y 1958, al significado de la reunión de cargos gobernador civil-jefe provincial en una misma persona y a la heterogénea interpretación que hacían los propios gobernadores acerca de lo que representaba el Movimiento. La segunda se centra en el comportamiento de los gobernadores con respecto al poder central que les había delegado la autoridad del mando en una provincia y, también, con respecto a los problemas, necesidades, intereses y, a veces, presiones organizadas de carácter local.

Mucho se ha escrito sobre el notable grado de poder de FET-JONS y su capacidad para estructurar la arquitectura del Nuevo Estado. A escala provincial los gobernadores civiles simbolizaban ese poder controlando desde el orden público hasta la configuración de las instituciones locales, más aún cuando se adhirió a ellos el cargo de jefe provincial del partido de manera generalizada para 1944. Esta identificación entre partido y Estado en la máxima autoridad en las provincias podría interpretarse como la prueba del establecimiento de un modelo fascista - al menos durante los primeros años cuarenta - caracterizado por el despliegue de un enorme poder de FET-JONS tal y como han puesto de relieve múltiples investigaciones ${ }^{16}$. La profunda renovación que se registró en el personal político vendría a avalar la evidencia del establecimiento de un nuevo régimen nacido de una guerra civil que habría hecho desaparecer en buena parte las estructuras precedentes. El partido habría procedido a la conquista del Estado y, como indica Marín, «no al revés, suponiendo que existiera algo llamado estado para poder conquistar y no un vacío provocado por el hecho de que el Estado había quedado al otro lado de

16 SANZ HOYA, 2008. ARCO BLANCO, 2013. MARÍN I CORBERA, nº 29 (Enero/Junio 2013). 
las barricadas ${ }^{17}$. Ahora bien, al analizar con mayor detalle los escenarios locales se observa un panorama sensiblemente distinto: no sólo se mantienen las instituciones como organismos administrativos (diputaciones, ayuntamientos) $\mathrm{y}$, pese a la represión, buena parte de su personal ${ }^{18}$; también sobrevivieron redes clientelares e influencias debidamente adaptadas al nuevo tiempo ${ }^{19}$.

A primera vista pudieran parecer excluyentes las dos interpretaciones aunque, en realidad, presentan áreas de compatibilidad si tenemos en cuenta los difusos perfiles del Movimiento y la capacidad del mismo para albergar, con mayor o menor comodidad, a los diversos grupos de la conjunción antirrepublicana. Los gobernadores civiles reflejaron bien ese limitadísimo pluralismo capaz de albergar diversas sensibilidades dentro de un sistema político antidemocrático y de partido único que, significativamente, fue convertido en movimiento. Recordemos que en 1939 se registra una victoria militar, no una victoria falangista. Los gobernadores eran todos jefes provinciales del Movimiento a partir de 1944, todos oficialmente falangistas pero con un origen heterogéneo: desde los realmente falangistas de primera hora hasta los monárquicos de diversa tendencia, pasando por tradicionalistas o cedistas y - como no- la legión de falangistas que se dieron de alta durante la guerra y la posguerra. Y no sólo es importante la delimitación de la procedencia ideológica; también la evolución posterior tiene gran importancia. El caso de un gobernador como Pedro Gamero del Castillo (de origen monárquico, luego falangista desde 1936, para volver a distinguirse como monárquico al abandonar los más altos cargos dentro del Movimiento) es elocuente pero no único. El perfil del ex dirigente de Renovación Española en Córdoba, José Tomás Valverde Castilla, gobernador en Sevilla (noviembre 1939-septiembre 1940), registra un recorrido de ida y vuelta similar, si bien de menor nivel. Cuando dejó de ser gobernador a causa de un enfrentamiento con el cardenal Segura se retiró de la vida pública oficial para retornar al ejercicio de la abogacía y a las filas monárquicas en el entorno de don Juan ${ }^{20}$. Otra buena muestra de escasa adhesión falangista se encuentra en la red formada por los gobernadores de Murcia (Carmelo Monzón 1939-1940), Valencia (Francisco Javier Planas Tovar, 1939-1943), Castellón (Martín Sada Moneo, 1939-1941) y Marcelino Ulibarri Eguilaz (delegado nacional para la recuperación de documentos en Salaman-

17 MARÍN I CORBERA, no 29 (Enero/Junio 2013): 292.

18 DÍAZ ARRIAZA, 2009: 298-213. Este trabajo demuestra la dureza de la represión pero, también, que la mayor parte del personal de las plantillas permaneció en sus puestos en el caso de las instituciones sevillanas.

19 CAZORLA SÁNCHEZ, no 4 (1999): 882-901. CAZORLA SÁNCHEZ y RODRÍGUEZ BARREIRA, $\mathrm{n}^{\circ} 229$ (2008): 471-501.

${ }^{20}$ El enfrentamiento puede consultarse en su archivo personal (Archivo José Tomás Valverde Castilla, Córdoba). El autor agradece al desaparecido Carlos Valverde Castilla la posibilidad de disponer de fotocopias de los originales. 
ca). Su correspondencia cruzada desvela la falta de sintonía con Falange al ser tan decididos anticomunistas y antimasones como convencidos tradicionalis$\operatorname{tas}^{21}$.

Durante los primeros años de la dictadura, en los que la Falange intentó monopolizar el Movimiento, la atmósfera se hizo irrespirable para algunos gobernadores ajenos a la ortodoxia monolítica que se quería imponer. Unos terminaron por abandonar el cargo, pero otros supieron esperar vientos más favorables. Y, al respecto, hemos de prestar atención a las transformaciones sutiles y graduales que experimentaron algunos gobernadores como producto de una adecuada adaptación. Ciertamente, el gobernador ostentaba una vertiente política como jefe provincial pero, como titular de un Gobierno Civil, era sobre todo Administración. En la misma medida en la que muchos gobernadores sentían el cargo de jefe provincial como un elemento añadido de segundo orden, fueron cobraron conciencia de ser autoridades cuyo poder era delegado y a las consignas de Madrid debían plegarse si aspiraban a continuar y promocionar en sus respectivas carreras políticas. Pecaríamos de cierta ingenuidad si intentásemos comprender a los responsables públicos y sus comportamientos en claves exclusivamente ideológicas. Es más: esa estrategia de acomodación no fue exclusiva de los gobernadores; otros muchos cargos y simples empleados públicos hicieron lo mismo. Y para ello convendría abrir nuevas perspectivas de análisis en un campo aún muy poco transitado: la historia social de la Administración.

Del gobernador no se esperaba ni originalidad, ni improvisación; se le había nombrado para resolver algunos problemas y no crear ninguno, para mantener en relativo orden su provincia y para ser transmisor de las pautas marcadas desde Madrid. Si un gobernador era lo suficientemente prudente y flexible, acrecentaba sus posibilidades de proseguir una carrera prometedora. En lo político era relativamente sencillo mantenerse dentro del Movimiento dado que distintas posiciones podían caber en él siempre que no se transgredieran ciertas líneas rojas, siendo la principal la lealtad al caudillo. Los gobernadores más perspicaces estaban atentos a los derroteros del gobierno, puesto que de una correcta percepción y una adecuada actuación dependía su carrera política. No es extraño, por tanto, que los gobernadores mantuvieran durante más tiempo sus mandatos a partir de 1945, ajustando cada vez más sus actuaciones en función de criterios de eficacia administrativa, enfriando los entusiasmos políticos de otrora. Esa actitud de adaptación tenía sus costes: en 1949, la Secretaría General del Movimiento tuvo que emitir una circular dirigida a los jefes provinciales para ordenarles que asistieran a sus despachos de las jefatu-

21 Esta correspondencia en: Centro Documental de la Memoria Histórica (CDMH), leg. 26, exp. 360 . 
ras todos los días pues muchos gobernadores se habían olvidado de ello 22 . Y es que a aquellas alturas ya tenían bastante trabajo en sus respectivos gobiernos civiles como para ocuparse encima de unas jefaturas que llevaban una vida cada vez más lánguida.

Hubo gobernadores que dieron muestras de extraordinaria habilidad para mantenerse en el cargo, como fue el caso del fiscal Antonio Rueda SánchezMalo al frente de las provincias de Almería (1945-1946), Cáceres (19461956), Álava (1956-1961), Navarra (1961-1962) y Valencia (1962-1973). Trayectorias como ésta no sólo era producto de una evolución acompasada con la del régimen, sino que también respondía a la adaptación a los criterios de reclutamiento de gobernadores. Fernando Herrero Tejedor, dos veces gobernador civil en los años 50, pronunció una conferencia en 1962 -ya convertido en vicesecretario general- donde dio cuenta de que más de la mitad de los gobernadores en esa fecha eran hombres «de ideas políticas basadas en los principios generales que informan el régimen desde un punto de vista amplio y comprensivo, sin extremismos». Y de una manera clara definió los criterios de selección entre los que la política jugaba un papel subsidiario:

En realidad, la tendencia dominante al valorar las condiciones personales de los futuros gobernadores y jefes provinciales, consiste en tener en cuenta la posible eficacia, la preparación técnica, el conocimiento de la realidad, la experiencia anterior en cargos representativos o de autoridad, y las dotes de mando que se calculan al candidato. La ideología política se valora indudablemente, pero en los términos generales e imprescindibles que hemos visto...23.

Resultaría interesante comparar el comportamiento de estos gobernadores con sus homólogos de otras etapas anteriores o posteriores. Naturalmente no nos referimos a sus perfiles ideológicos sino a sus pautas de actuación y sus relaciones tanto con el gobierno que los designó como con las provincias que hubieron de gobernar. Y cabe preguntarse si los desvelos de un gobernador en los años veinte o treinta se diferenciaban sustancialmente de los del primer franquismo, teniendo en cuenta que la estructura administrativa del Estado obedecía a similares parámetros y cultura gestora, sobre todo en lo tocante a la administración local ${ }^{24}$. Pero lo que en todo caso parece claro es que, al consolidarse el franquismo, los gobernadores (tanto los de más edad como los de menos) fueron adquiriendo un perfil de fieles sirvientes dotados de experien-

22 Archivo General de la Administración (en adelante AGA), leg. 51/20789. El delegado nacional de provincias, Tomás Romojaro, informaba al secretario general del «estado de atonía política y de malestar interno dentro de la Organización»: AGA, leg. 51/20779.

23 HERRERO TEJEDOR, 1962: 43-44.

24 Una muestra de los desvelos de un gobernador durante la República en APARICIO ALBIÑANA, 1936. 
cia (en la burocracia del Movimiento o en la administración local), tenían preparación técnica (mayoritariamente en derecho), se les suponía eficaces (resolución de problemas), estaban dotados de capacidad de mando (autoridad) y eran presumiblemente «conocedores de la realidad». Para los años sesenta esos perfiles de pericia técnica y eficacia se intensificarían en la segunda generación del Movimiento ${ }^{25}$. Y esos rasgos podían verse realzados o no en relación con la provincia de destino.

Hace ya años Canales Serrano puso de manifiesto que las lógicas de la victoria del franquismo no presentaban la misma intensidad. La victoria social fue en gran medida alcanzada a golpe de represión, miedo, prevención y el fomento de unos ciertos grados de apoyo obtenidos a través de múltiples procedimientos (cabe añadir al respecto que una historia social de la burocracia del Movimiento o de la estructura administrativa probablemente arrojaría resultados interesantes). Pero la victoria política resultó más precaria en virtud de la competencia interna entre los diversos sectores ideológicos del régimen $^{26}$. Ante ese panorama no resulta extraña la relativa brevedad de los mandatos de los gobernadores en los primeros años de dictadura, tal y como hemos visto. Sólo en la medida en que las luchas internas remitieron y el franquismo se consolidó, los gobernadores comenzaron a prolongar sus mandatos y a incrementar la rotación entre provincias. La intensidad de los problemas políticos disminuyó y la gestión de las provincias (según los intereses y conveniencias del gobierno) pasó a ocupar un lugar central. No fue casual que se elaborase el decreto de gobernadores de 1958 con la intencionalidad de potenciar los gobiernos civiles como los impulsores del desarrollo provincial.

En otras palabras: para la designación de gobernadores se tenían en cuenta tanto las características de la provincia como la adecuación del designado para ese destino. La hipótesis contraria nos conduciría a la contemplación de un Estado perfectamente centralizado que repartía gobernadores en distintas combinaciones sin preocuparse de mucho más. La receta que aplicaba un gobernador en una provincia podía ser idéntica a la que aplicaba en otra. Y si bien no caben dudas razonables sobre la centralización del estado franquista, tampoco puede negarse que las influencias y presiones locales jugaron un papel. El viejo caciquismo de la Restauración y el sistema caciquil habían desaparecido hacía lustros, pero los notables y los grupos de presión podían hacer notar su influencia incluso hasta Madrid. En 1955, el viejo cacique granadino Natalio Rivas no estaba ya en condiciones de sacar adelante a su candidato a procurador en Cortes, tal y como informó el entonces gobernador (Servando Fernández-Victorio Camps) a la Delegación Nacional de Provincias ${ }^{27}$.

25 GIL PECHARROMÁN, 2013: 37.

26 CANALES SERRANO, 1995: 74-82.

27 AGA, leg. 51/19075. 
Pero también era cierto que prohombres locales se enfrentaron a gobernadores que no sintonizaron con sus provincias y, tarde o temprano, terminarían siendo destituidos. El ex alcalde de León durante la dictadura de Primo de Rivera y hombre de Renovación Española, Francisco Roa de la Vega, sostuvo tensas relaciones con gobernadores de mandato intenso pero breve. Con sus influencias favoreció el cese de alguno, se enfrentó a otro y, tras sufrir un benigno destierro en La Bañeza y Segovia, consiguió volver a León donde ya mantuvo excelentes relaciones con gobernadores procedentes - como éldel mundo del derecho ${ }^{28}$.

No es este el lugar para un análisis pormenorizado caso por caso que nos permita establecer unos patrones con los que construir modelos explicativos de mayor precisión. Será objeto de otros trabajos el estudiar con detalle aquellas provincias o áreas de mayor inestabilidad en los gobiernos civiles. Ejemplo puede ser el caso de las cuatro provincias gallegas, de alta inestabilidad media destacándose Pontevedra, que viene a coincidir con los problemas de aquella región para la construcción del Nuevo Estado, tal y como ha puesto de manifiesto Grandío Seoane, entre otras investigaciones ${ }^{29}$.

\section{A MODO DE COLOFÓN}

El 21 de abril de 1941, el gobernador de Córdoba — Rogelio Vignote - se quejaba de la actitud del jefe provincial de Milicias, Fernando Coca de la Piñera. Vignote lo acusaba de no liderar las milicias a su cargo, ni asistir a la Fiesta de la Unificación celebrada unos días antes. Igualmente, Coca de la Piñera era un ausente habitual en las reuniones del Consejo Provincial pero, sin embargo, no faltó el día de los funerales de Alfonso XIII aunque bien distanciado de los jerarcas de FET-JONS. Ante tal proceder, el gobernador se lamentaba de la «actitud de desobediencia e indisciplina» de $\mathrm{Coca}^{30}$. La paradoja vendría meses después cuando Coca de la Piñera fue designado gobernador civil de Jaén (1941-1943) y, posteriormente, de Sevilla durante un largo mandato (1943-1949). Era un simple ejemplo — uno más - de las diferentes actitudes que cabían dentro del Movimiento. Y lo significativo es que quienes abogaban por el predominio falangista no tendrían carreras tan prometedoras al frente de gobiernos civiles como otros, más templados ideológicamente pero dotados de mayor capacidad de adaptación. Significativas fueron también las diferencias entre el I y el II Consejo Nacional de Jefes Provinciales, celebrados en 1943 y 1949 respectivamente. En el primero, una de las ponen-

28 ROA RICO, 1998.

29 GRANDÍO SEOANE, $\mathrm{n}^{\circ} 6$ (2001); pp. 215-228.

30 AGA, leg. 51/20548 
cias estaba dedicada a estudiar las relaciones entre el Estado y el Partido abogando, naturalmente, por un mayor protagonismo de éste último. En el siguiente Consejo Nacional se hablaba ya sobre la diferencia entre Estado y Partido, dentro de una atmósfera palpable de burocratización del Movimiento. Es curioso comprobar que la documentación del I Consejo se localiza entre los papeles de la Secretaría Política de la Secretaría General del Movimiento; la del II Consejo permaneció relegada en la Delegación Nacional de Provincias. Algo había cambiado, hasta la importancia otorgada a los Consejos Nacionales de jefes provinciales.

\section{Bibliografía}

Aguilar, Miguel Ángel, Las últimas Cortes del franquismo, Barcelona, Avance, 1976.

Álvarez Álvarez, Julián, Burocracia y poder politico en el régimen franquista, Madrid, INAP, 1984.

Aparicio Albiñana, José, Para qué sirve un gobernador... Impresiones ingenuas de un ciudadano que lo ha sido dos años de las provincias de Jaén y Albacete, Valencia, La Semana Gráfica, 1936.

Arco Blanco, Miguel Ángel del, «¿Fascismo en las instituciones del franquismo?» Coloquio Identidades fascistas. Fascistización y desfascistización e España, Universidad Autónoma de Barcelona, 2013. Disponible en: http://grupsderecerca. uab.cat/republicaidemocracia/sites/grupsderecerca.uab.cat.republicaidemocracia/f iles/P_ARCO.pdf. [consultado el 26 de febrero de 2014]

Baena dē Alcázar, Mariano, Élites y conjuntos de poder en España (1939-1992). Un estudio cuantitativo sobre Parlamento, Gobierno y Administración y gran empresa, Madrid, Tecnos, 1999.

Bañón Martínez, Rafael, Poder de la burocracia y Cortes franquistas (1943-1971), Madrid, INAP, 1978.

Balfour, Sebastian, «La dictadura franquista y los modelos totalitarios y autoritarios en Europa», en Navajas Zubeldia, Carlos y Iturriaga Barco, Diego (coords.), Crisis, dictaduras, democracia: I Congreso Internacional de Historia de Nuestro Tiempo, Logroño, Universidad de La Rioja, 2008; 39-43.

Beltrán Villalba, Miguel, La élite burocrática española, Madrid, Ariel-Fundación Juan March, 1977.

Bernal García, Francisco, El sindicalismo vertical. Burocracia, control laboral y representación de intereses en la España franquista (1936-1951), Madrid, Centro de Estudios Constitucionales-Asociación de Historia Contemporánea, 2010.

Cajal Valero, Arturo, El gobernador civil y el Estado centralizado en el siglo XIX, Madrid, INAP, 1999.

Calvo Vicente, Cándida, «Los gobernadores civiles en Guipúzcoa durante el primer franquismo», en Tusell Gómez, Javier (coord.), El régimen de Franco, 19361975: política y relaciones exteriores, Madrid, UNED, 1993, I; 19-28. 
Canales Serrano, Antonio Francisco, «Las lógicas de la victoria. Modelos de funcionamiento político local y provincial bajo el primer franquismo», II Encuentro de Investigadores del Franquismo, Alicante, Instituto de Cultura Juan Gil-AlbertFEIS, 1995; 74-82.

Cazorla Sánchez, Antonio, «Dictatorship from Below: Local Politics in the Making of the Francoist State, 1937-1948», The Journal of Modern History, 4 (Dec. 1999), 882-901.

Cazorla Sánchez, Antonio y Rodríguez Barreira, Óscar, «Hoy Azaña, mañana... Franco: una microhistoria de caciquismo en democracia y dictadura. Berja (Almería), 1931-1945», Hispania, 229 (2008), 471-501.

Cerón Torreblanca, Cristian Matías, «La paz de Franco». La posguerra en Málaga: desde los oscuros años 40 a los grises años 50, Málaga, Universidad, 2007.

Clara, Josep, «Militarismo político y gobiernos civiles durante el franquismo», Anales de Historia Contemporánea, 18 (2002), 451-468.

Clara, Josep, «La transición vista desde los gobiernos civiles», Anales de Historia Contemporánea, 20 (2004); 143-166.

Clara, Josep, «El Gobernador, el Prefecto y los exiliados republicanos en los Pirineos orientales», Anales de Historia Contemporánea, 23 (2007), 573-596.

Cobo Romero, Francisco y Ortega López, Teresa María, Franquismo y posguerra en Andalucía oriental. Represión, castigo a los vencidos y apoyos sociales al régimen franquista, 1936-1950, Granada, Universidad, 2005.

Dávila y Fernández de Celis, Sancho, Las Cortes españolas, Madrid, Impr. Magerit, 1971.

Díaz Arriaza, José, «Depuración de funcionarios y empleados del Ayuntamiento y Diputación de Sevilla», en Cuesta, Josefina (coord.) La depuración de funcionarios bajo la dictadura franquista, 1936-1975, Madrid, Fundación Largo Caballero, 2009: 298-311. Disponible en: http:/www.todoslosnombres.org/php/verArchivo. php?id=4950. [Consultado el 24 de febrero de 2014].

Díaz Nosty, Bernardo, Las Cortes de Franco: 30 años orgánicos, Barcelona, Dopesa, 1972.

Dóriga Tovar, César, «El cargo de Gobernador Civil y Jefe Provincial del Movimiento en el Nuevo Estado español», Revista de Estudios Políticos, 156 (nov/dic 1967), 145-167.

García Mañá, Luis Manuel, De los corregidores a los gobernadores civiles de Orense, Madrid, Secretaría General Técnica del Ministerio del Interior, 1986.

García Ramos, Domingo, Instituciones y vida política durante la guerra civil y el franquismo. Palencia (1939-1975), Madrid, UNED, 2003.

Garrorena Morales, Ángel, Autoritarismo y control parlamentario en las Cortes de Franco: apuntes para un análisis crítico, Murcia, Universidad, 1977.

Gil Pecharromán, Julio, El Movimiento Nacional (1937-1977), Barcelona, Planeta, 2013.

González Madrid, Damián-Alberto, “Gobernadores y prefetti (1922-1945)» en $V$ Encuentro de investigadores del franquismo, (Albacete, 2003). Las ponencias de este encuentro en: Ortiz Heras, Manuel (coord.), Memoria e Historia del fran- 
quismo. V Encuentro de Investigadores del franquismo, Albacete, Universidad de Castilla-La Mancha, 2005.

Grandío Seoane, Emilio, «Problemas en la construcción del "Nuevo Estado"» (Galicia 1936-1939)», Historia y Comunicación Social, 6 (2001), 215-228.

Herrero Tejedor, Fernando, La figura del gobernador civil y jefe provincial del Movimiento, Madrid, Nuevo Horizonte, 1962.

Maestre Rosa, Julio, Procuradores en Cortes: 1943-1976, Madrid, Tecnos, 1977.

Marín i Corbera, Martí, «Los gobernadores civiles del franquismo, 1936-1963: Seis personajes en busca de autor», Historia y Politica, 29 (Enero/Junio 2013), 269-299.

Mercadal Bagur, Deseado, El mando civil en Menorca: subgobernadores y delegados del gobierno (1857-1998), Menorca, Edicions Llevant, 1998.

Mirambell i Belloc, Enric, Historia del Gobierno Civil de Girona, Madrid, Ministerio del Interior, 1992.

Moreno Sáez, Francisco, «La transición en Alicante vista desde el Gobierno Civil», Calendura, 2 (2000), 71-130.

Navajas Zubeldia, Carlos y Rivero Noval, M. C., «La militarización del Gobierno Civil de la provincia de Logroño en las dictaduras de Primo de Rivera y Franco: análisis comparativo», Berceo, 128 (1995), 215-228.

Nicolás Marín, María Encarna, «Los gobiernos civiles en el franquismo: la vuelta a la tradición conservadora en Murcia (1939-1945)», en Tusell, Javier y et al. (eds.), El régimen de Franco (1936-1975). Política y relaciones exteriores, Madrid, UNED, 1993; 135-150.

Nicolás Marín, María Encarna, «Los poderes locales y la consolidación de la dictadura franquista», Ayer, 33 (1999), 65-86.

Nieto García, Alejandro, «Afirmación, apogeo, decadencia y crisis de los cuerpos de funcionarios», en VV.AA., Estudios sobre la burocracia española, Madrid, Instituto de Estudios Políticos, 1974.

Ortiz Heras, Manuel, «El liderazgo de los gobernadores civiles como institución básica de la administración provincial», II Encuentro de Investigadores del Franquismo, vol. I, Alicante, Instituto de Cultura Juan Gil-Albert-FEIS, 1995, 181-188.

Pemartín, José, ¿Qué es «lo nuevo»? Consideraciones sobre el momento español presente, Madrid, Espasa-Calpe, 1940.

Pérez de la Canal, Miguel Ángel, Notas sobre la evolución del régimen legal de los gobernadores civiles (1812-1958), Madrid, Secretaría General Técnica del Ministerio de la Gobernación, 1964.

Pernaute, $\mathrm{M}^{\mathrm{a}}$ Ángeles, El poder de los cuerpos de burócratas en la organización administrativa española, Madrid, INAP, 1978.

Ponce Alberca, Julio (coord.), Guerra, Franquismo y Transición. Los gobernadores civiles en Andalucía (1936-1979), Sevilla, Centro de Estudios AndalucesConsejería de Presidencia, 2008.

Ponce Alberca, Julio, «El Estado en las provincias: gobernadores, diputaciones y ayuntamientos», en Nicolás, Encarna y González, Carmen, Mundos de ayer, Murcia, Universidad, 2009; 99-122. 
Ponce Alberca, Julio, «Poder, adaptación y conflicto. Gobernadores civiles e intereses locales en la España de Franco (1939-1975)», en Segura, Antoni, Mayayo, Andreu y Abelló, Teresa (eds.), La dictadura franquista: la institucionalización de un régimen, Barcelona, Universitat de Barcelona, 2012; 96-109.

Richard, Bernard, «Étude sur les gouvernements civils en Espagne de la Restauration à la Dictadure (1874-1923). Origine géographique, fonctions d'origine et évolution d'un personnel politico-administratif», Mélanges de la Casa de Velázquez, VIII (1972), 441-474.

Risques, Manuel, El Govern Civil de Barcelona al segle XIX, Barcelona, Publicacions de Labadía de Montserrat, 1995.

Risques, Manuel, L'Estat a Barcelona: Ordre public i governadors civils, Barcelona, Editorial Base, 2012.

Roa Rico, Juan Manuel, Francisco Roa de la Vega y los gobernadores civiles, León, Imprenta Moderna, 1998.

Rodríguez González, Javier, León bajo la dictadura franquista (1936-1951), León, Universidad de León, 2003.

Sánchez Brun, Gaudioso, Instituciones turolenses durante el franquismo (1936-1961). Personal y mensaje político, Teruel, Instituto de Estudios Turolenses, 2002.

Sánchez Brun, Gaudioso, «El mensaje político de los gobernadores turolenses (19361961)», en II Encuentro de Investigadores del Franquismo. Alicante, 11-13 de mayo de 1995, I, Alicante, Instituto Juan Gil-Albert, 1995.

Sanz Alberola, Daniel, La implantación del franquismo en Alicante: el papel del Gobierno Civil (1939-1946), Alicante, Universidad, 1999.

Sanz Hoya, Julián, «Camarada gobernador. Falange y los gobiernos civiles durante el primer franquismo», en Nicolás Marín, María Encarna y González Martínez, Carmen (coords), Ayeres en discusión [recurso electrónico], Murcia, Universidad, 2008. Disponible en: http://dialnet.unirioja.es/servlet/libro?codigo=399225 [consultado el 24 de febrero de 2014].

Serrallonga i Urquidi, Joan, "El aparato provincial durante la Segunda República. Los gobernadores civiles, 1931-1939», Hispania Nova. Revista de Historia Contemporánea, 7 (2007). Disponible en: http://hispanianova.rediris.es/7/articulos/7a008.pdf [consultado el 26 de abril de 2014]

Serrano Suñer, Ramón, Entre Hendaya y Gibraltar, Madrid, Ediciones y Publicaciones Españolas, 1947.

Serrano Suñer, Ramón, Memorias: entre el silencio y la propaganda, la historia como fue, Barcelona, Planeta, 1978.

Serrats Urquiza, Salvador, Presente y futuro de las cortes españolas, Cádiz, Caja de Ahorros, 1974.

Tébar Hurtado, Javier, Barcelona, Anys Blaus. El governador Correa Veglison: poder i politica franquistas (1940-1945), Barcelona, Flor del Vent, 2011.

Thomàs, Joan María, «La configuración del franquismo: el partido y las instituciones», Ayer, 33 (1999), 41-64. 
Vega Sombría, Santiago, «El papel de los gobernadores civiles en la implantación del régimen de Franco. Las circulares de Manuel Pérez Mirete», en Ortiz Heras, Manuel (coord.), Memoria e Historia del franquismo. V Encuentro de Investigadores del franquismo, Albacete, Universidad de Castilla-La Mancha, 2005; publicado en CD.

Viver Pi-Sunyer, Carles, El personal politico de Franco (1936-1945): contribución empirica a una teoría del régimen franquista, Barcelona, Ed. Vicens-Vives, 1978.

VV.AA., El Gobernador civil en la política y en la Administración de la España contemporánea, Madrid, Ministerio del Interior, 1997.

Recibido: 03/07/2014

Aceptado: 14/07/2015 